\title{
Using Porcine Acellular Collagen Matrix (Pelvicol®) in Bladder Augmentation: Experimental Study
}

\author{
Ali Ayyildiz, Baris Nuhoglu, Emre Huri, Elif Ozer, Mesut Gurdal, Cankon Germiyanoglu \\ Urology and Pathology Clinics, Ankara Training and Education Hospital, Ministry of Health, \\ Ankara, Turkey
}

\begin{abstract}
Purpose: Evaluate the rabbit augmented bladder with Pelvicol ${ }^{\circledR}$.

Materials and Methods: Twenty New Zealand rabbits were divided into 4 groups. Bladder augmentation was performed using a $10 \times 10 \mathrm{~mm}$ sized porcine acellular collagen matrix. The material was placed on the dome of the bladder wall as a patch with 5-0 polyglycolic sutures. The bladder was resected on the 7th, 14th day, 30th and 90th days, and processed for histological analysis.

Results: No stone formation was found in the first, second and fourth weeks. In the first week, there was inflammatory appearance and roughness in the reconstructed area when compared to other sites on the bladder wall. The material could not be seen in some bladders because of acute inflammatory reaction. The normal bladder epithelium was found on the part of the bladder wall that follows the surface of the eroded material. In the second week, edema was observed through the bladder wall. Perivesical fat tissue increased and it was not easy to distinguish it from the surrounding area. In the fourth week, the bladder wall was thickened and there was a sensation of hardness present. The inner and outer surface of the material was darker than in the other bladders. In the third month, there was no inflammatory reaction; however, there was micro calcification and irregular detrusor regeneration.

Conclusions: Pelvicol ${ }^{\circledR}$ cannot be suitable material for bladder augmentation because of the resultant micro calcification, thickening of the bladder wall and irregular development of detrusor regeneration.
\end{abstract}

Key words: bladder; reconstructive surgical procedures; collagen; swine; experiments; rabbits

Int Braz J Urol. 2006; 32: 88-93

\section{INTRODUCTION}

The ileocystoplasty technique is generally used for bladder augmentation for a variety of benign and neoplastic urological disorders. It is also associated with many complications, such as infection, bladder wall weakness, stone formation, electrolyte imbalance and intestinal perforations $(1,2)$. For these reasons, new biomaterial or synthetic ma- terials are tested for use appropriately in augmentation of the urinary bladder; however there is no material currently available for use in bladder augmentation. The ideal materials should be immediately epithelialized after surgery and adapt to the bladder through muscular and neovascular regeneration. They should also be waterproof and reach high capacity with low pressure as a reservoir in the bladder $(3,4)$. An acellular tissue matrix graft was first described in 1975 (5). It is produced by extract- 
ing cells from the extra cellular matrix through a multistep chemical and enzymatic process. This extraction leaves behind a sheet of homogeneous extra-cellular matrix consisting primarily of collagen and elastin. Porcine acellular collagen matrix $\left(\right.$ Pelvicol $\left.^{\circledR}\right)$ is a material that has been used clinically in vaginal wall prolapse (6), Peyronie's disease (7) and pubovaginal slings (4). It is also non-allergenic and resistant to collagenase. It was approved by the FDA in 2000. It is a unique biomaterial characterized by a number of different positive features. By using a natural, three-dimensional, acellular biomaterial called porcine collagen matrix in bladder augmentation, we test its harmony with the normal bladder according to macroscopical and histopathological findings.

\section{MATERIALS AND METHODS}

In this study, 20 New Zealand rabbits were used. Consent was obtained from the local ethics committee. Rabbits were divided into four groups according to the evaluation time after surgery. They were anesthetized with $10 \mathrm{mg} / \mathrm{kg}$ ketamine and $3 \mathrm{mg} / \mathrm{kg}$ xyalazine i.v. Intravenous penicillin was administered for antibiotic prophylaxis. Following the cleansing of the area, the abdomen was entered through a $2 \mathrm{~cm}$ low midline abdominal incision. Bladder reconstruction was performed using a $10 \times 10 \mathrm{~mm}$ sized porcine acellular collagen matrix $\left(\mathrm{Pelvicol}^{\circledR}\right)$. The material was placed on the dome of the bladder wall as a patch using 5-0 polyglycolic sutures. Perivesical fat tissues were replaced on the outer surface of the material. The bladder was resected in the first sacrificed group on the 7th day, in the second group on the 14th day, in the third group after the first month and in the fourth group after the third month. Bladders were kept in formaldehyde solution. Later, $5 \mu \mathrm{m}$ cross sectional samples were prepared and stained with hematoxylin-eosin for histological analyses. During the early and late periods, the histopathological effects of the Pelvicol $^{\circledR}$ on the host tissue and bladder wall were investigated and a macroscopic evaluation was performed. The samples obtained on the 7th and 14th days and after the first and third months were compared.

\section{RESULTS}

We did not observe any intraoperative or postoperative complications. There were no urinary extravasations. No stone formations were discovered on macroscopic evaluation during the first and second weeks and after the first month. In the first week, the bladder was completely protected, although there was inflammation and roughness in the reconstructed area when compared with the other bladder areas. The material could also e seen in some bladders because of the dense tissue reaction. A microscopic evaluation confirmed polymorph nuclear leukocyte infiltration (PNL) because of the acute inflammation. A normal bladder epithelium was found in the part of the bladder wall that follows the surface of the eroded material. There were no findings of epithelization or neovascularization (Figure-1). In the second week, edema was observed through the bladder wall. Perivesical fat tissue also increased and was not easy to distinguish from the surrounding area. Epithelization and neo-vascularization was still not found. After the first month, abscess formation was noted in one bladder in the entire area adjacent to the material, and there was a homogeneous thickness and roughness along the entire wall of the bladder. The inner and outer surface of the material were darker than the remaining tissues in the other bladders and

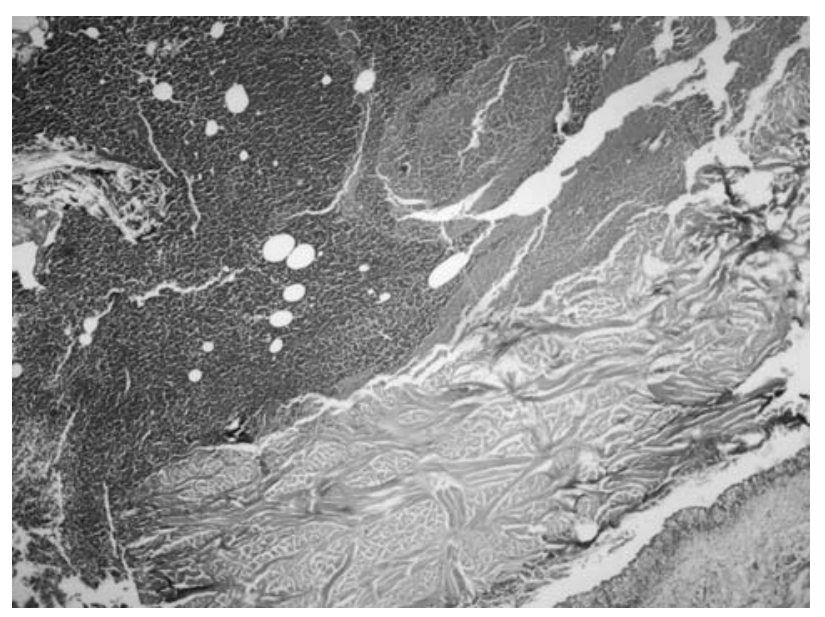

Figure 1 - First week, histopathological examination. Note dense tissue reaction, acute inflammation, and eroded bladder mисоsa (HE, X100). 
the material was distinguished clearly from the adjacent tissue. A minimal contraction of the material was observed (Figure-2). There were no findings of epithelization and neo-vascularization, and micro calcification was observed through the bladder wall. After the third month, there was no urine extravasation and tissue thickness like a granuloma was observed in the grafted area. However, the material could not

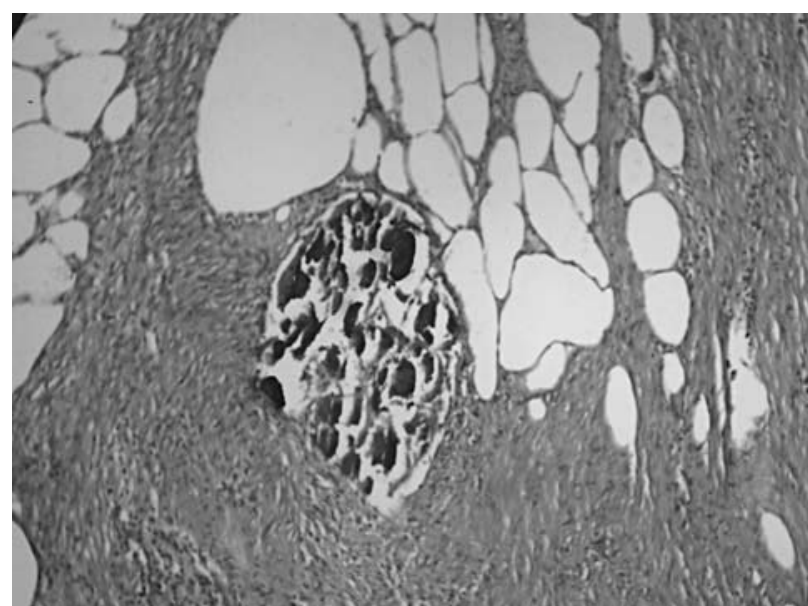

Figure 2 - After first month, histopathological examination. The material was darker and distinguished clearly from the adjacent tissue (HE, X40). be distinguished clearly from the bladder wall. Microscopic evaluation confirmed epithelization that continued as a normal bladder epithelium, micro calcification of the material, irregular detrusor regeneration and disarrangement of the smooth muscle fibers that migrated into the material and neo-vascularization. There were no findings of inflammatory reaction, Figure- 3 and Table- 1.

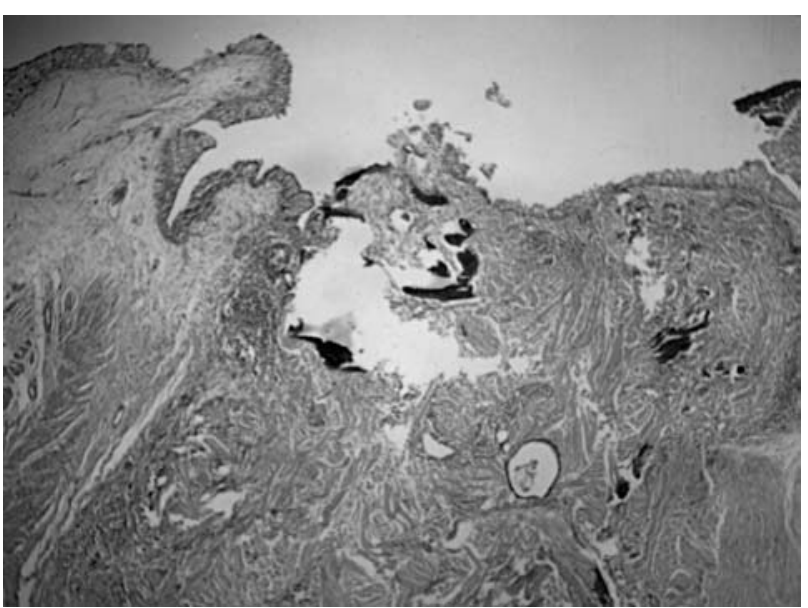

Figure 3-After the third month, histopathological examination. Note microcalcification, disarrangement of muscle fibers that migrated into the material and neovascularization (HE, X100).

Table 1 - Macroscopic and microscopic evaluation.

\begin{tabular}{lcccc}
\hline & $\mathbf{7}$ days & $\mathbf{1 4}$ days & $\mathbf{3 0}$ days & $\mathbf{9 0}$ days \\
\hline Macroscopic evaluation & & & & - \\
Stone formation & - & - & - & - \\
Extravasation & - & - & + & - \\
Inflammatory reaction & + & + & + & + \\
Edema & - & - & + & + \\
Retraction of the material & - & + & + & + \\
Thickness of the bladder wall & + & & - & + \\
Microscopic evaluation & & + & - & + \\
Inflammation & + & - & - & + \\
Erosion of the bladder mucosa & + & - & - & + \\
Re-epithelization & - & - & - & + \\
Neo-vascularization & - & - & & + \\
Microcalcification & - & - & & \\
Irregular detrusor regeneration & - & & & + \\
\hline
\end{tabular}




\section{COMMENTS}

Bladder augmentation is the treatment of a wide variety of clinical conditions in the practice of urology. Generally in this operation, the intestinal segment has been used to maintain a large bladder capacity and low pressure during the postoperative follow-up, although side effects may be present during this period. The intestinal segment was first used in 1888 for the reconstruction of a dysfunctional bladder (8), and many reports were present in the literature especially after 1950 concerning the use of intestinal segments for bladder reconstruction. Currently, alternative methods that decrease morbidity and operating time are being researched, and biomaterials such as acellular collagen matrix, small intestinal submucosa, free fascial graft, omentum, bovine pericardium, human placenta, and duramater are being evaluated for use in urological surgery. Only a few reports are present in the literature about the use of these materials in bladder augmentation (9), although the use of synthetic materials such as polytetrafluoroethylene (Gore-Tex) grafts in the reconstruction of the urinary bladder has been reported in animal models (10). Bladder substitutes should also be biocompatible and able to promote bladder regeneration by acting as a biodegradable scaffold to support cell growth and differentiation. Thus, the appropriate inner and outer surfaces of the bladder wall that are free of urine extravasations through the patchy area are obtained regularly.

We used a porcine acellular dermal collagen matrix as a biomaterial for bladder augmentation. The structure of the Pelvicol implant is cross-linked, which renders it permanent. One of the advantages of this material over synthetic products is that natural grafts can often be left in place if infection occurs. Sutherland et al. described the use of alloplastic acellular tissue matrix allografts from the stomach or bladder in a rat model (11). The outcome was excellent and featured complete epithelization of the luminal surface of the graft after 4 days, and evidence of vascular and muscle regeneration within 2 weeks. In comparison with this study, we did not evaluate epithelization and neovascularization in the luminal surface of the material in 2 weeks. Acute inflammatory reactions were present on the surface of the material as a scaffold in the bladder wall. We determined epithelization, irregular detrusor regeneration and neovascularization on the surface and around the material at the 3 month point as a long-term result of the study. Urine extravasation was not observed in reconstructed bladders, except in one case that presented an abscess formation in the perivesi$\mathrm{cal}$ area. This shows that the acellular collagen matrix graft for bladder augmentation is generally urine impermeable. Presence of PNL infiltration on the inner surface of the material at 1 month revealed the lack of biocompatibility of this material, although the knowledge about this subject in the literature is poor. In addition, it may cause the contraction and shrinkage of the bladder wall and decrease the capacity of the bladder over the long-term (12).

Portis et al., however, found mucosal formations in the 6th week in the laparoscopic bladder augmentation of mini pigs using acellular tissue matrix (12). They also found neovascularization in the third month upon cystoscopic evaluation. The contraction rate for the acellular tissue matrix at the end of the third month was $70 \%$. We did not report any serious contraction and fibrosis in reconstructed areas. Piechota et al. reported that these regenerated bladders exhibited $80 \%$ of the contractile activity of a native bladder under electrical stimulation and muscarinic, purinergic, and $\alpha$ and $\beta$-adrenergic drug administration $(13,14)$. There was a $63 \%$ incidence of bladder stone formation in this animal model. We, however, did not encounter bladder stones in any of our animals, although microcalcified focuses were observed irregularly among the smooth muscle fibers at 3 months. This may lead to stone formation during the late followup period. It is understood that using the intestinal segment in bladder augmentation may cause a stone formation in the bladder, too. In addition, experience to date with Pelvicol ${ }^{\circledR}$ has shown that the graft may still be present without re-absorption up to 3 years after surgery (15).

\section{CONFLICT OF INTEREST}

None declared. 


\section{REFERENCES}

1. Gleason DM, Gittes RF, Bottacini MR, Byme JC: Energy balance of voiding after cecal cystoplasty. J Urol. 1972; 108: 259-64.

2. Elder JS, Snyder HM, Hulbert WC, Duckett JW: Perforation of the augmented bladder in patients undergoing clean intermittent catheterization. J Urol. 1988; 140: 1159-62.

3. Reddy PP, Barrieras DJ, Wilson G, Bagli DJ, McLorie GA, Khoury AE, et al.: Regeneration of functional bladder substitutes using large segment acellular matrix allografts in a porcine model. J Urol. 2000; 164: 936- 941.

4. Speakman MJ: Bladder augmentation cystoplasty with a novel collagen membrane. BJU Int. 2000; 85: 2-3 (Abst \#42).

5. Meezan E, Hjelle JT, Brendel K: A simple versatile nondisruptive method for the isolation of morphologically and chemically pure basement membranes from several tissues. Life Sci. 1975; 17: 1721-32.

6. Ruparelia BA, Gunasheela D, Sundar K: Worcester Royal Infirmary NHS Trust, UK. International Urogynecological Association Abstract. 2000.

7. Lloyd SN, Hetherington J: St James's Hospital, Leeds and Princess Royal Hospital, Hull, UK. British Association of Urological Surgeons. 2000.
8. Tizzoni G, Foggi A: Die Wiederherstellung der Harnblase. Zentralbl. Chir. 1888; 15: 921-23.

9. Gleeson MJ, Griffith DP: The use of alloplastic biomaterials in bladder substitution. J Urol. 1992; 148: 1377-82.

10. Senel FM, Akman RY, Arýkan AY, Gurdal M, Can C: The use of polytetrafluoroethylene (Gore-Tex) grafts in reconstruction of the urinary bladder. Int Urol Nephrol. 1999; 31: 313-9.

11. Sutherland RS, Baskin LS, Hayward SW, Cunha GR: Regeneration of bladder urothelium, smooth muscle, blood vessels and nerves into an acellular tissue matrix. J Urol. 1996; 156: 571-7.

12. Portis AJ, Elbahnasy AM, Shalhav AL, Brewer A, Humphrey P, McDougall EM, et al.: Laparoscopic augmentation cystoplasty with different biodegradable grafts in an animal model. J Urol. 2000; 164: 1405-11.

13. Piechota HJ, Dahms SE, Probst M, Gleason CA, Nunes LS, Dahiye R, et al.: Functional rat bladder regeneration through xenotransplantation of the bladder acellular matrix graft. Br J Urol. 1998; 81: 548-59.

14. Piechota HJ, Dahms SE, Nunes LS, Dahiya R, Lue TF, Tanagho EA: In vitro functional properties of the rat bladder regenerated by the bladder acellular matrix graft. J Urol. 1998; 159: 1717-24.

15. Stuart NL, William C: The current use of biomaterials in Urology. European Urology (Suppl.) 2002; 1: 2-6.

Accepted after revision: September 30, 2005

Correspondence address:

Dr. Ali Ayyildiz

Dikmen cad. 55. Sok.

Özümit sitesi K Blok 8/35

Keklikpinari-Dikmen, Ankara, Turkey

E-mail: urology52@yahoo.com

\section{EDITORIAL COMMENT}

Currently, the use of bowel segments is the mainstay for bladder augmentation; however, they have clear disadvantages, such as a lack of contractility requiring frequent clean intermittent catheter- ization, mucous production with the consequent urinary tract infection and calculus formation and less frequently, cancer development. A good solution for this problem would be the organized re-growing of 
the bladder wall over an appropriate scaffold in order to preserve all functions. The search for this material is extensive, and many have been tested over time. The problem is that the scaffold is occupied by the host cells in a disorganized fashion resulting in an inactive and frequently contracted tissue segment.
Probably the cause of this is our lack of understanding about the intrinsic regulatory mechanisms that could promote the growing of a new ordered and functionally active bladder segment. We look forward to further research to address this important issue.

\author{
Dr. Paulo R. Monti \\ Associated Professor of Urology \\ Federal University of Triângulo Mineiro \\ Uberaba, Minas Gerais, Brazil \\ E-mail: montipr@terra.com.br
}

\section{EDITORIAL COMMENT}

This paper deals with the use of heterologous material for bladder augmentation.

It has been shown in many publications that almost everything sutured over a normal resected bladder will allow for epithelialization; there are reports of the use of paper, silicone, rubber etc. All of these alloplastic prostheses were used for total or partial augmentation. Replacements were applied as temporary implants and removed after bladder regeneration $(1,2)$.

The problem remains in obtaining muscle proliferation. By using a non-absorbable material, the authors have shown what has already been shown. Probably this material could be used as a scaffold to allow bladder epithelium and muscle to be seeded and thus form a new bladder wall. There is a recent paper by Kimulli et al. where a similar material has been utilized as a scaffold with very promising results (3).

This paper has the merit of showing that these materials should not be used as a substitute for the bladder wall.

The authors state in their introduction that there is no material suitable for bladder augmentation. This is not true. In 15 years of work in experimental models and clinical experience with close follow-up, we have shown that the demucosalized bowel fulfills the prerequisites for an ideal material (4). It is easily available, doesn't promote the reabsorption of electrolytes or stone formation, and maintains good bladder compliance. The long-term complication rate in this series is around 10\%, which is far distant from that reported for total intestinal patches (33\%) (5).

\section{REFERENCES}

1. Shokeir AA: Bladder regeneration: between the idea and reality. BJU Int. 2002; 89: 186-93.

2. Elbahnasy AM, Shalhav A, Hoenig DM, Figenshau RT, Clayman, RV: Bladder wall substitutes with synthetic and non-intestinal organic materials. J Urol. 1998; 159: 628-7.

3. Kimuli M, Eardley I, Southgate J: In vitro assessment of decellularized porcine dermis as a matrix for urinary reconstruction. BJU Int. 2004; 94: 859-66.

4. Lima SV, Araujo LA, Vilar FO, Kummer CL, Lima EC: Nonsecretory sigmoid cystoplasty: experimental and clinical results. J Urol. 1995; 153: 1651-4.

5. Lima SV, Araujo LA, Vilar FO: Nonsecretory intestinocystoplasty: a 10-year experience. J Urol. 2004; 171: 2636-39; discussion 2639-40.

Dr. Salvador Vilar C. Lima Associated Professor of Urology Federal University of Pernambuco Recife, Pernambuco, Brazil E-mail: salvilar@salvador.net 